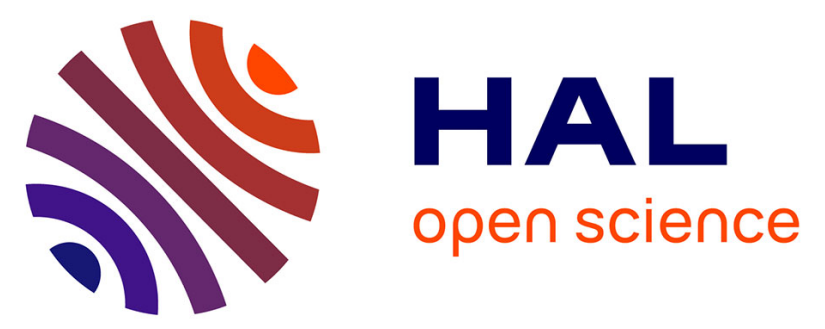

\title{
Ion current density profiles in negative corona gaps versus EHD confinements
}

A. Bouarouri, N. Jidenko, F. Gensdarmes, D. Maro, D. Boulaud, J.-P. Borra

\section{To cite this version:}

A. Bouarouri, N. Jidenko, F. Gensdarmes, D. Maro, D. Boulaud, et al.. Ion current density profiles in negative corona gaps versus EHD confinements. Journal of Electrostatics, 2016, 82, pp.88-95. 10.1016/j.elstat.2015.08.005 . hal-02558448

\section{HAL Id: hal-02558448 \\ https://hal.science/hal-02558448}

Submitted on 1 Jun 2021

HAL is a multi-disciplinary open access archive for the deposit and dissemination of scientific research documents, whether they are published or not. The documents may come from teaching and research institutions in France or abroad, or from public or private research centers.
L'archive ouverte pluridisciplinaire HAL, est destinée au dépôt et à la diffusion de documents scientifiques de niveau recherche, publiés ou non, émanant des établissements d'enseignement et de recherche français ou étrangers, des laboratoires publics ou privés.

\section{(ㅇ)(1) $\$$}

Distributed under a Creative Commons Attribution - NonCommercial - NoDerivatives $\mid 4.0$ 


\title{
Ion current density profiles in negative corona gaps versus EHD confinements
}

\author{
A. Bouarouri ${ }^{(a)}$, N. Jidenko ${ }^{(a)}$, F. Gensdarmes ${ }^{(b)}$, D. Maro ${ }^{(b)}$, D.Boulaud ${ }^{(b)}$, J.-P. Borra ${ }^{(a)}$ \\ ${ }^{a}$ Lab Phys Gaz \& Plasmas, CNRS, Univ. Paris Sud, CentraleSupelec, Université Paris-Saclay, F- \\ 91405, Orsay, France. \\ ${ }^{\mathrm{b}}$ Institut de Radioprotection et de Sûreté Nucléaire (IRSN) PSN-RES/SCA/LPMA, PRP- \\ ENV/SERIS/LRC, PRP-ENV/DIR, Gif-sur-Yvette, 91192, France.
}

\begin{abstract}
This paper deals with the electric and hydrodynamic confinement of negative ions in a point-to-plane corona discharge gap. Radial ion current density profiles have been measured on the earthed planar electrode, drilled in the axis of the point. The experimental setup is first validated by comparison with the Warburg's law without injected gas flow rate. The gas injected in the gap and blown from the discharge gap through the hole located at the centre of the plane affects neither the electric field close to the point nor the subsequent electric wind. However, it leads to the confinement of ions flux towards the central symmetry axis in the low electric field region up to a critical gas velocity, which for no more effect is measurable. Hence, electro hydro-dynamics confinement of ions can be achieved by limiting the outward radial expansion of ions to increase ion current densities on specific locations close to the low field planar electrode.
\end{abstract}

\section{Introduction}

Thanks to various electrode configurations and operating conditions, Coronae are used for electrostatic filtration and separator [1-3], chemical analysis [4], ozone generation [5], heat and mass transfers [6-7]. For all these applications, controlling the ion fluxes in the gap is critical to control the process. With the self-induced "ion wind" (cf. §2) and no injected gas flow, the radial distribution of ions in the low field region close to the planar electrode, related to the current density measured on the earthed plane is known to evolve with the applied voltage of the point and versus the geometry of the gap [8]. Thus, many modelling works have been developed to study the Electro-Hydro-Dynamics (EHD) flow in coronaes to account for the self-induced ion wind [9-10].

In this work, a point-to-drilled plane corona discharge is used to produce negative ions for aerosol charging downstream the discharge gap, hereafter referred as post-discharge. As proposed by Whitby to avoid aerosol losses by electro-collection in the gap [11] and still under investigations [12-14], a gas flow is used to blow ions from the gap through a hole drilled in the earthed electrode to the post-discharge charging zone. This implies aerosol charging in much lower post-discharge ion densities than in the gap. The mean number of charges per particle depends on the particle diameter and on the $N_{i}$.t product (with $N_{i}$, the ion density and $t$ the transit time of aerosol in this ion density). Post-corona unipolar aerosol chargers thus usually lead to higher charged aerosol concentration, but to lower mean number of charges per particle than when aerosol is injected in the discharge gap. To increase the ion density in the post-corona charging volume, the effect of the gas flow on ion extraction has been studied.

Since the ion flux extracted from the discharge gap necessarily depends on the ions density distributions in the gap, this paper focuses on the effect of the gas flow velocity on the current density and on the electric field in the gap, especially just next to the extraction hole drilled in the low field planar electrode, as already described with a gas flow perpendicular to the point axis [15] or in a wire-to-plates electroprecipitator [16].

After an introduction of the theoretical background on EHD induced by ion fluxes in a discharge gap, the experimental set-up is first validated and calibrated to account for the effects of the connection tracks and of the insulating surfaces between these conductive tracks used for ion current density measurement on the low field drilled planar electrode. Then, the effect of the gas flow on the radial distribution of ion current density measured on the earthed plane $(j(r)$, the current density profile in $A \cdot \mathrm{m}^{-2}$ ) is presented and discussed for different applied voltages, point radii and gap lengths. 
Doing so, both electrostatic and hydrodynamic confinement of ions in the central axis of the point close to the low field drilled planar electrode are reported and discussed.

\section{Theoretical background of the study}

In negative point-to-plane corona, the negative ions produced by the plasma are accelerated by the Coulomb force and move towards the grounded plane. The high-frequency collisions between ions and neutral air molecules slow down ions and produce the EHD gas flow, known as the ion or electric wind [17]. The ions drift velocity is given by $\mu_{i} \cdot \vec{E}$ with $\mu_{i}$ the mean mobility of ions, $\vec{E}$ the electric field. In each point of the gap, the ion current density depends on the electrostatics drift, advection and diffusion:

$$
\vec{J}=N_{i} \cdot\left(\mu_{i} \cdot \vec{E}+\vec{v}\right)-D_{i} \cdot \nabla N_{i}
$$

where $N_{i}$ is the ion density, $\vec{v}$ the gas velocity and $D_{i}$, the mean diffusion coefficient of ions. In most cases, the diffusion process can be neglected. Moreover, the gas velocity (related either to the ion wind or to the injected air flow, most often below $10 \mathrm{~m} . \mathrm{s}^{-1}$ ) can be neglected compared to the electrostatic one (above 10 m.s ${ }^{-1}$ ).

In 1889, Warburg has measured the current density profile in a point-to-plane corona discharge, with the self-induced ion wind and without injected gas flow. To do so, an earthed plane made of flat concentric metal rings has been used to define an empirical law [8] :

$$
\begin{array}{cc}
j(r)=J(0) \cdot \cos ^{m} \theta(r) & \text { for } \theta<60^{\circ}, \\
j(r)=0 & \text { for } \theta \geq 60^{\circ} ; \\
\text { with } J(0)=\alpha \cdot V \cdot\left(V-V^{\circ}\right) / d^{n} \sim 1 /\left(k \cdot d_{\text {gap }}{ }^{2}\right)
\end{array}
$$

where $J(0)$ is the axial peak current, $\theta$ is the semi-vertical cone angle of the discharge given by: $\theta=\tan ^{-1} r / d_{\text {gap }}$. where $r$ is the radial planar coordinate an $d_{\text {gap }}$ is the gap length. Warburg and other authors $[8,18-19]$ define the power $\mathrm{m}$ and the coefficient $k$ ( $m=4.82$ for positive polarity and 4.65 for negative polarity and $k \sim 2$ ). The Warburg's law is the result of the EHD competition in the discharge gap controlling the transport of ion. Electrostatic forces depend on the electric field (Laplace and space charge fields). Hydrodynamic forces depend on the relative velocity of ion and neutral molecule, controlled by the electric wind [20].

Warburg's law, set for centimetre gap, has been confirmed for millimetre and centimetre gaps $[9,17,21,22]$ up to several meters by Allibone [23]. Goldman et al. have reported some dimples in the axial peak current and defined an approximation of the axial peak current $j(0)=l / k d_{g a p}{ }^{2}$, with $k=2$ [16]. Theoretical EHD analyses have been conducted by Sigmond [20] and Jones [23] with examples given in Refs. [9, 25, 26].

\section{Materials and methods}

The experimental set-up is depicted in Figure 1. The measurements are carried on at room temperature between 18 and $25^{\circ} \mathrm{C}$.

The active electrode (metal point) is a tungsten needle with a radius of curvature from 26 to $132 \mu \mathrm{m}$. The earthed electrode is a printed circuit board composed of seventeen concentric copper rings (width between 1.5 and $1.625 \mathrm{~mm}$ ) insulated from each other by a $0.5 \mathrm{~mm}$ width epoxy resin.

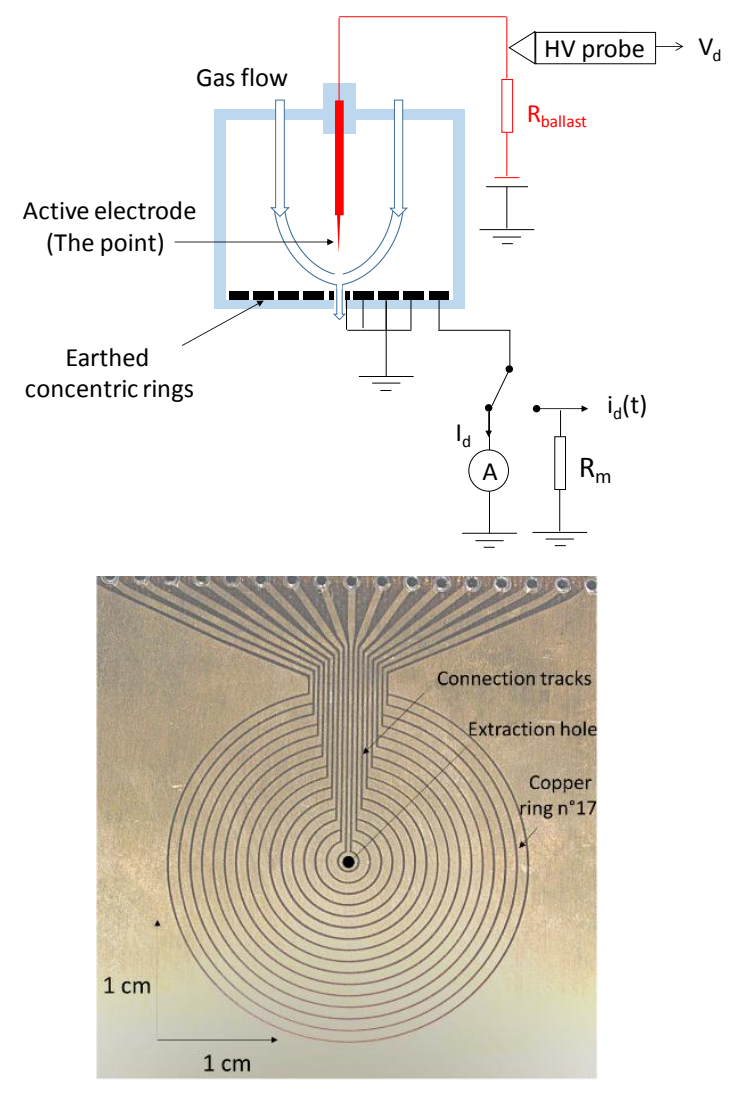

Figure 1. Experimental setup used for discharge characterization and current density profile measurements.

The point is connected to a negative high voltage power supply through a resistor $\left(R_{\text {ballast }}=10 \mathrm{M} \Omega\right)$. This resistor induces a voltage drop $\left(\Delta V=R_{\text {ballast. }} I_{\text {discharge }}\right)$. The voltage of the point $\left(V_{d}\right.$, in $\left.V\right)$ is measured with a high voltage probe. The discharge current $\left(I_{d}\right.$, in A) is measured with all the rings connected to an electrometer and visualised with an oscilloscope through a resistor $\left(R_{m}\right)$. A resistor of either $50 \Omega$ or $10 \mathrm{k} \Omega$ is used for the characterization of the Trichel pulses and the mean discharge current respectively. Both negative current and voltage are given and plotted in absolute value.

The distance between the walls of the cylinder and the point $\left(D_{\text {walls-point }}\right)$ is chosen to limit the modification of the radial electric field and the related ion distribution in the gap 
$\left(D_{\text {walls-point }}=65 \mathrm{~mm}>5 . d_{\text {gap }}\right)$. The pressure in the gap is 1020 mbar, whatever the gas flow rate is.

The clean and dry air flow (without aerosol, concentration of volatile organic compounds $<10$ ppmv, relative humidity $<5 \%$ ) is controlled by a mass flow metres from 0 to 30 L. $\mathrm{min}^{-1}$. The gas flow is injected far above the point $(150 \mathrm{~mm})$ on the whole section of the reactor using grids to reach laminar flow. The injected gas velocity around the point is about $1 \mathrm{~m} . \mathrm{s}^{-1}$, far below the ions one $\left(\sim 100 \mathrm{~m} \cdot \mathrm{s}^{-1}\right)$.

To compute the $j(r)$ profile, the current of each metal ring is divided by the apparent areas $\left(A_{i}{ }^{3}\right)$ of the ring (as detailed in $\$ 4.1 .2$ and Table 1). The current density profiles are plotted versus the mean radius $r_{i}$ of each ring calculated by $r_{i}=\left(r_{i-1}{ }^{\text {out }}+r_{i}^{\text {out }}\right) / 2$ with $r_{i}^{\text {out }}$ the outer diameter of the $i^{\text {th }}$ ring, for $1<i \leq 17$. Using these mean radii as abscises of $j(r)$ to plot the values calculated as described in $\S$ 4.1.2 induces a shift of the $j(r)$ profile towards the centre. The maximal radial shift has been evaluated to $0.2 \mathrm{~mm}$ for the second ring (using Warburg's law and the apparent ring area) and is reported as horizontal error bars on all $j(r)$ figures. The central disc electrode is too large to enable one to measure the dimple described in Ref. [18] but this is out of the scope of this study.

The experiments without injected gas flow were conducted with a full planar electrode with a central disc electrode $\left(\mathrm{N}^{\circ} 1\right.$ with a radius of $1.6 \mathrm{~mm}$ and an area of $8.2 \mathrm{~mm}^{2}$, cf. table 1). For the experiments with the injected gas flow, the central disk is drilled, the diameter of the hole is $D_{\text {hole }}=2 \mathrm{~mm}$; leading to a first ring (width of $0.6 \mathrm{~mm}$ and area of $5.2 \mathrm{~mm}^{2}$ ).

\section{Results}

\subsection{Validation of the experimental setup}

\subsubsection{Discharge characterization}

A corona is a self-sustained discharge where the inhomogeneous electric field confines the ionization processes around the electrode with the smaller radius of curvature. Positive ions are produced by gas ionization and negative ions by electron attachment. These processes depend on the reduced electric field $E / N$, with $E$, the electric field and $N$, the gas density. The Laplace electric field depends on the discharge voltage $\left(V_{d}\right)$, on the curvature radius of the point $\left(R_{p}\right)$, and on the gap length $\left(d_{g a p}\right)$.

Above a threshold voltage, depending on the gap length, on the point radius and on the pressure, the discharge is ignited. Then, in negative polarity, two main regimes of discharge are observed. At increasing voltage, the discharge current includes current pulses of about $1 \mathrm{~mA}$ and $10 \mathrm{~s} \mathrm{~ns}$ duration called Trichel pulses. The frequency of the pulses lies between few tens to few hundreds $\mathrm{kHz}$. For higher voltages, the discharge current in the Corona regime is continuous without pulses. For intermediate voltages (between Trichel and Corona regimes) both regimes occur on a voltage range, which depends on the $R_{\text {Ballast }}$.

The corona discharge current can be written as $I_{d}=A \cdot V_{d^{\prime}}\left(V_{d^{-}} V^{\circ}\right)$ where $V^{\circ}$ is the onset voltage and $A$ is a constant $\left(\mathrm{F} . \mathrm{s}^{-1}\right)$ depending on the geometry and on the ion mobility [20].

Different gaps $(4,8,11.5$ and $13 \mathrm{~mm})$ and point radius $(26,60,80$ and $132 \mu \mathrm{m})$ have been tested. The ratio of the discharge current by the point voltage is plotted versus the point voltage in Figure 2 for a point radius of $R_{p}=80 \mu \mathrm{m}$ and a gap length of $d_{\text {gap }}=13 \mathrm{~mm}$.

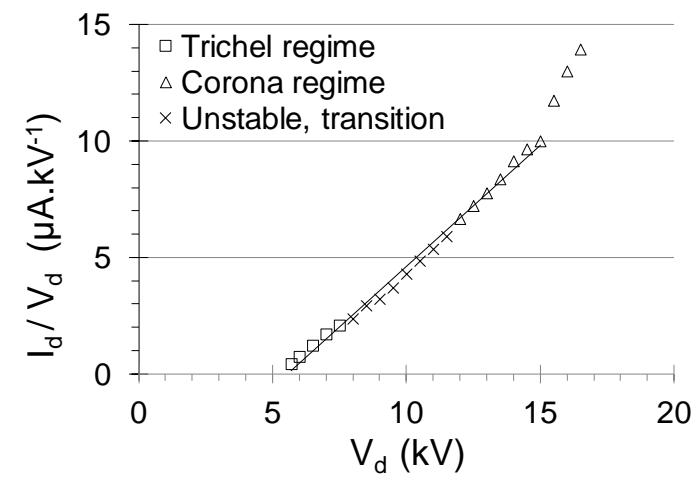

Figure 2. $I_{d} / V_{d}$ versus $V_{d}$ for $R_{p}=80 \mu \mathrm{m}, d_{g a p}=13 \mathrm{~mm}$, $P=1020$ bar, $Q=30$ L.min ${ }^{-1}$.

As expected for self-sustained corona, the ratio of the discharge current over the voltage $\left(I_{d} / V_{d}\right)$ increases linearly with the voltage up to at least $100 \mu \mathrm{A}(150 \mu \mathrm{A}$ for a $13 \mathrm{~mm}$ gap in Figure 2). The slope of the curve depends on gap geometry and ion electrical mobility. This confirms the reliability of discharge currents, detailed below, and voltage measurements.

\subsubsection{Current density profile on the plane $j(r)$}

The mean current density for a ring was first estimated by the ratio of the ring current (i.e. the measured current minus the current collected on the connective track estimated by integrating Warburg's law over the surface of the track) to the real area of the ring. Doing so, the current densities were overestimated for the all the rings except the first one, compared to Warburg's law. Actually, ions that would be collected on the non-conductive surfaces between successive metal rings are repealed by the space charge electric field to the external ring.

Assuming that ions above the non-conductive surface are drained to the outer rings, the apparent surfaces of collection have been calculated as the sum of the geometric area of 
the ring plus the area of the internal nonconductive ring: $A_{i}{ }^{\prime}=\Pi \cdot\left[\left(r_{i}^{\text {out }}\right)^{2}-\left(r_{i-1}^{\text {out }}\right)^{2}\right]$, for $i \geq 2$. Table 1 gives the inner radius $\left(r_{i}^{i}\right)$, the mean radius $\left(r_{i}\right)$, the geometric area $\left(A_{i}\right)$ and the mean apparent area $\left(A_{i}\right)$ of each ring. The two values for the first ring concern the full and drilled planes.

Table 1: Inner and mean radius as well as geometric and apparent areas of the rings

\begin{tabular}{|c|c|c|c|c|}
\hline $\begin{array}{c}\text { Ring } \\
\mathrm{N}^{\circ} \mathrm{i}\end{array}$ & $\begin{array}{c}\text { Outer } \\
\text { radius } \\
\mathrm{r}_{i}{ }^{\text {uut }} \\
(\mathrm{mm})\end{array}$ & $\begin{array}{c}\text { Mean } \\
\text { radius of } \\
\text { ring } \\
\mathrm{r}_{i}(\mathrm{~mm})\end{array}$ & $\begin{array}{c}\text { Geometric } \\
\text { area of the } \\
\text { ring } \\
A_{i}\left(\mathrm{~mm}^{2}\right)\end{array}$ & $\begin{array}{c}\text { Apparent } \\
\text { area } \\
A_{i}{ }^{\prime}\left(\mathrm{mm}^{2}\right)\end{array}$ \\
\hline 1 & 1.625 & $0.81 / 1.43$ & $8.30 / 5.20$ & $8.3 / 5.2$ \\
\hline 2 & 3.5 & 2.56 & 26.2 & 28.8 \\
\hline 3 & 5.25 & 4.37 & 40.4 & 45.8 \\
\hline 4 & 7 & 6.12 & 56.0 & 64.0 \\
\hline 5 & 8.75 & 7.87 & 71.4 & 82.0 \\
\hline 6 & 10.62 & 9.69 & 94.6 & 108 \\
\hline 7 & 12.5 & 11.6 & 112 & 128 \\
\hline 8 & 14.25 & 13.4 & 119 & 138 \\
\hline 9 & 16 & 15.1 & 134 & 156 \\
\hline 10 & 17.87 & 16.9 & 162 & 186 \\
\hline $11-$ & 23.25 & 20.6 & 566 & 646 \\
13 & & & & 1135 \\
\hline $14-$ & 30.5 & 26.9 & 997 & \\
\hline 17 & & & & \\
\hline
\end{tabular}

Figure 3 depicts the ion current density profiles calculated from the measured currents on each ring and from Warburg's law for a gap length $d_{g a p}=11.5 \mathrm{~mm}$ and a point radius $R_{p}=60 \mu \mathrm{m}$, for a large voltage range (8-18.5 kV for Trichel or Corona regimes). The terms $J(0)$ in Warburg's law are calculated from the total discharge current $l_{d}$, according to eq.2.

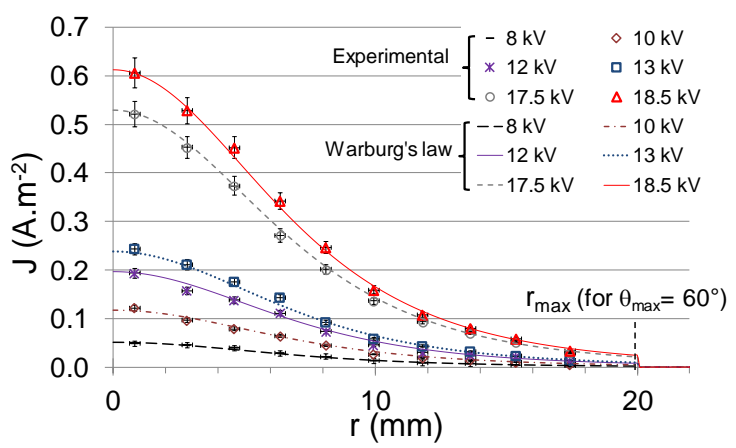

Figure 3. Ion current density profiles for corona and Trichel regimes $\left(R_{p}=60 \mu \mathrm{m} ; d_{g a p}=11.5 \mathrm{~mm}\right)$.

The measured and theoretical current density profiles are in agreement within 5\% (vertical error bars in Figure 3). These discrepancies are related to uncertainties of measurements and of Warburg's parameters $(m, k)$. In the literature, the $m$ coefficient varies from 4.5 to 5.5 [22] due to electrostatic effects (such as point holder polarization, that affects the Laplace electric field) or hydrodynamic effects (modification of the ion wind due to walls too close to the point) or the modification of the mean ion mobility related to gas impurities $\left(\mathrm{H}_{2} \mathrm{O}\right.$, VOC, aerosol... also affecting $\left.k\right)$. Nevertheless, these approximations do not affect the validity of the results presented here, which are based on the comparison of the ion current density profiles always calculated with the same approximations, in the same gas, with different operating conditions (by modifying either the Laplace electric field or the gas flow rate).

The validity of the apparent surfaces has been confirmed for gap lengths of 8 and $10 \mathrm{~mm}$. Additional measurements with different points confirm that the point radius (from $30,60,80$ to $130 \mu \mathrm{m})$ has no effect on $j(r)$ profiles [20]. The resolution of the ion density measurements evolves with the ring area from $5 \cdot 10^{-3} \mathrm{~A} \cdot \mathrm{mm}^{-2}$ for the first ring $\left(\mathrm{N}^{\circ} 1\right)$ to $5 \cdot 10^{-5}$ for the last ring (with a resolution on the ion current of $50 \mathrm{nA}$ for the $1 \mu \mathrm{A}$ full scale range). The minimal resolution is reached for the first rings where the ion density current is maximal. The resolution is lower than $1 \%$ on the measured ion densities current whatever the ring is.

\subsection{Effect of a polarized annular electrode}

To investigate the influence of the Laplace electric field modification on the $j(r)$ profile, a negatively polarized annular electrode is inserted in the gap between the point and the plane. The polarized annular electrode modifies the Laplace electric field and thus the ion current density profiles in the gap.

Two main constraints have been taken into account to size and locate in the gap the annular electrode. The first one is to avoid the ion collection on the annular electrode. To do so, the annular electrode is located outside the drifting zone, using an inner radius larger than $r_{\max }$ (for $\vartheta=60^{\circ}$ ). The second constraint is to limit the electric field created by the polarized annular electrode in the plasma volume (close to the point). A distance of $5 \mathrm{~mm}$ between the plane and the annular electrode is chosen, for a gap length $d_{g a p}=13 \mathrm{~mm}$ (cf. Figure 8 ). The $j(r)$ profiles with a annular electrode voltage of $V_{a}=0$ or $4 \mathrm{kV}$ are plotted in Figure 4 .

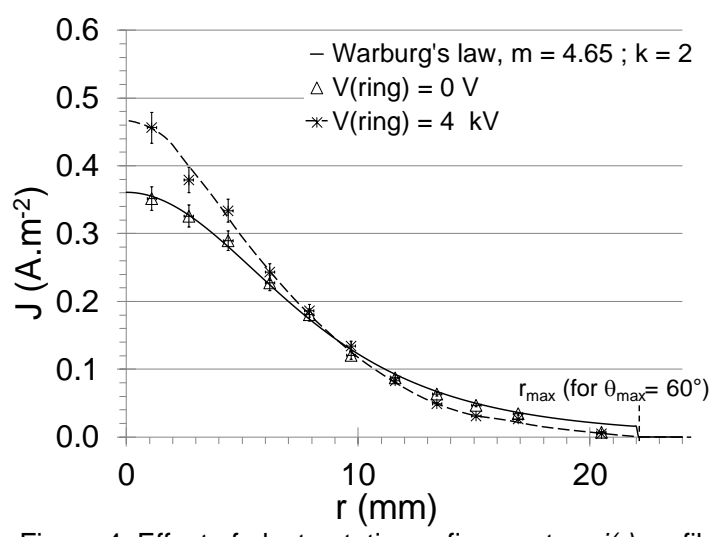

Figure 4. Effect of electrostatic confinement on $j(r)$ profile $\left(R_{p}=80 \mu \mathrm{m} ; d_{g a p}=13 \mathrm{~mm} ; V_{d}=17 \mathrm{kV}, I_{d}=118 \mu \mathrm{A}, V_{a}=4 \mathrm{kV}\right)$ 
Except for the last rings ( $\left.n^{\circ} 14-17\right)$, the $j(r)$ profile obtained without polarization of the annular electrode $\left(V_{a}=0\right)$ is identical with the one predicted by Warburg's law. The grounded ring has thus a minor effect on ions dispersion.

However, for $V_{a}=4 \mathrm{kV}$, the modification on $j(r)$ due to electrostatic confinement is highlighted with this setup. The $j(r)$ profile evolves with higher current densities for the four central rings (e.g. for $30 \%$ increase from 0.36 to $0.46 \mathrm{~A}^{\mathrm{mm}} \mathrm{m}^{-2}$ on the first ring) and lower further from the point axis, than expected from Warburg's law.

\section{3. $j(r)$ with a drilled plane}

Before dealing with the effects of the gas flow on the ion production $\left(I_{d}\right)$ and on the ion distribution on the earthed plane $(j(r))$, the full and drilled planes are first compared. The discharge current and the current density profiles are measured for two voltages in both Trichel $(9 \mathrm{kV})$ and Corona (17 kV) regimes, for the full plane (without hole) and for the drilled plane, without injected gas flow.

For the same voltage, the discharge current is identical on both planes. A small fraction of the ion current gets through the hole due to the electric wind or/and the electric field lines crossing the hole to end on the underlying earthed surface on the drilled plane electrode, downstream the discharge gap. The ion current measured downstream the hole using a grid located at $5 \mathrm{~cm}$ from the hole represents from 0.001 to $1 \%$ of $I_{d}$ (cf. $\$ 4.5$ ). However, with the sensitivity of the current measurement, the hole drilled in the earthed plane does not affect the current-voltage characteristic of the discharge.

The $j(r)$ are plotted in Figure 5 for the full and drilled plane, calculated with the apparent areas given in table 1. Except for the first ring (encircled data points), the current density profile for the full and drilled planes, are similar within $5 \%$ in both Trichel and Corona regimes. The hole has a negligible effect on the discharge current and the related ion density current profile is slightly affected, but to a smaller extent than the measurement uncertainties.

The currents measured on the first central ring are similar with the full and the drilled planes. This proves that most of the electric field lines that end on the central disc for the full plane still end on the first ring with the drilled plane. Even if some ions enter the hole, they are mainly collected on the walls of the hole and drained to the first ring. Then, since both currents collected are similar on two very different surfaces with the full central disc or on the first ring around the hole, the ion density current on this first central ring with the drilled plane is higher than the one on the central disc with the full plane, as depicted with encircled data points in Fig. 6. Hence, the evaluation of the ion density current on this first central ring is not relevant and not presented below.

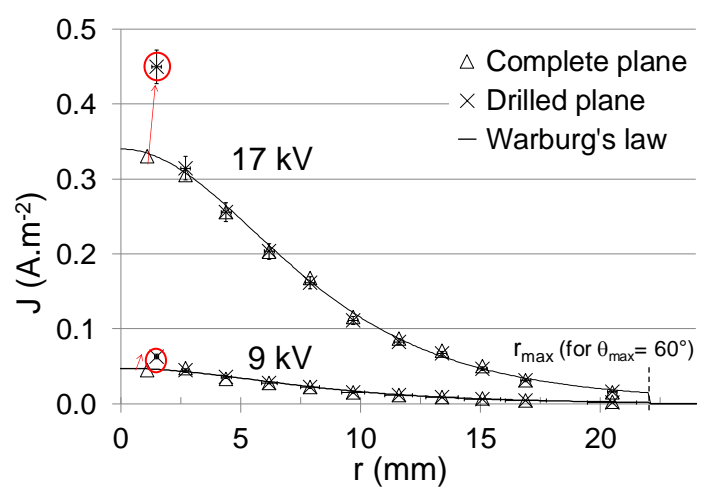

Figure 5. Comparison of planar current density j(r) for a plane and a drilled plane $d_{g a p}=13 \mathrm{~mm}$.

As a result, the following reported effects of hydrodynamic confinement evaluated from the evolution of profiles of ion density current on all rings except the first one, only arise from gas flow injection.

\subsection{Effect of the injected gas flow on $j(r)$}

To quantify the effect of the injected gas flow on the current density profile, $j(r)$ is estimated on the plane with the drilled plane and a gas flow rate from 5 to 30 L.min ${ }^{-1}$. As $j(r)$ with injected gas flow depicted on Fig 7, is close to Warburg's law, a $\cos ^{m}$ law is used to fit the measurements. A chi-square test is performed to evaluate the power $m$ ' and the coefficient $k^{\prime}$ from the experimental $j(r)$ profiles.

The discharge parameters used are those given above $\left(R_{p}=80 \mathrm{~mm}, d_{g a p}=13 \mathrm{~mm}\right)$ with a hole diameter of $D_{\text {hole }}=2 \mathrm{~mm}$. The pressure in the discharge chamber is $102 \mathrm{kPa}$ whatever the gas flow rate is.

The data for gas flow rates of 5 and 30 L. $\mathrm{min}^{-1}$ and for both Trichel $\left(V_{d}=9 \mathrm{kV}\right)$ and Corona $\left(V_{d}=17 \mathrm{kV}\right)$ regimes are depicted in Figure 6.

As for the polarized annular electrode (cf. §4.2), the gas flow induces higher current densities on the first four central rings for $r<8$ $\mathrm{mm}$ (i.e. for $\theta<32^{\circ}$ and, for $d_{\text {gap }}=13 \mathrm{~mm}$ ) and lower densities further from the point axis than without injected gas flow, despite a constant $I_{d}\left(V_{d}\right)$ characteristic whatever the injected flow rate is. In other terms, ion flux confinement towards the central symmetry axis in the low field region can be achieved in discharge gaps either by electrostatic focussing with a polarized annular electrode inserted in the gap or by hydrodynamic focussing with a gas flow 
injected in the gap and blown from the discharge gap through the hole located at the centre of the plane.
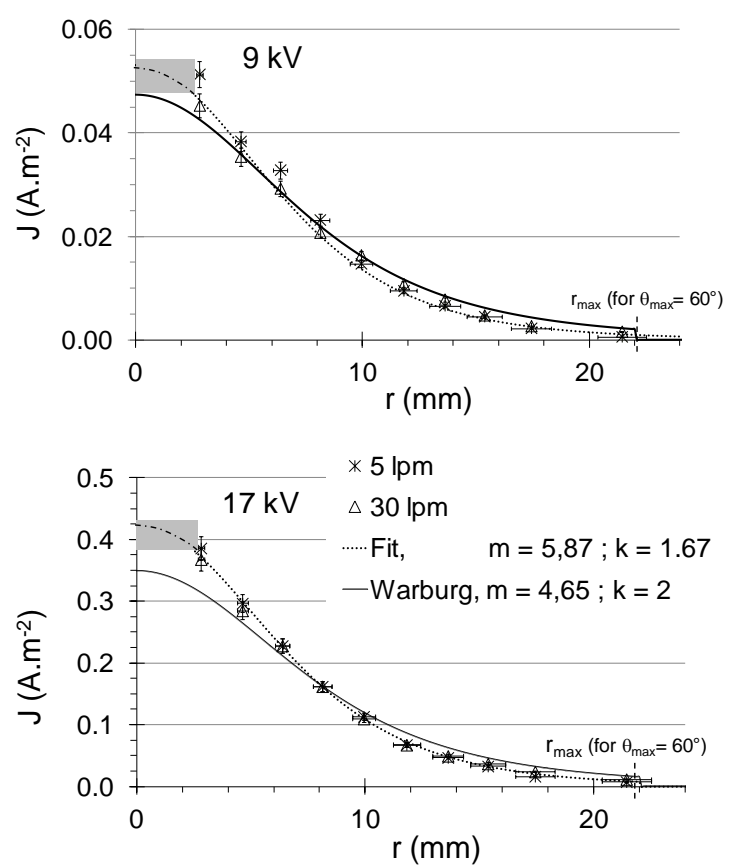

Figure 6 . The ion current density profiles measured at $9 \mathrm{kV}$ and $17 \mathrm{kV}$ (dashed line) and calculated from Warburg's law for negative polarity ( $m=4.65$; full line).

The current density profiles evolve with the gas flow rate from 0 to 5 L. min $^{-1}$ but not anymore from 5 to 30 L.min ${ }^{-1}$. By analogy with Warburg's law, the evolution of the power $m$ ' and the coefficient $k$ are plotted in Figure 7 versus the gas flow rate at $17 \mathrm{kV}$ as well as at $9 \mathrm{kV}$ (not presented here).

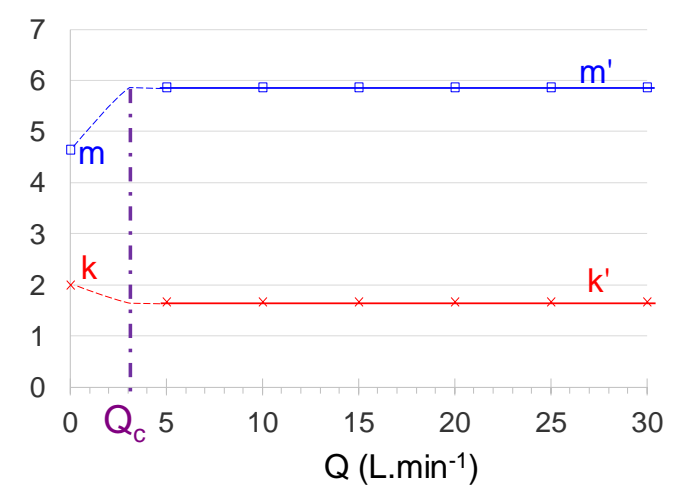

Figure 7. Evolution of the power $m$ ' and the coefficient k' with gas flow rate

The power $m$ ' increases with the gas flow when the coefficient $k$ ' decreases until a critical flow rate " $Q_{c}$ " smaller than 5 L.min ${ }^{-1}$. Both of these factors saturate for higher gas flow rate up to at least $30 \mathrm{~L} \cdot \mathrm{min}^{-1}$. A higher power $\mathrm{m}^{\prime}$ (5.87 instead of $m=4.65$ ) and a smaller coefficient k' (1.67 instead of $k=2)$ are estimated, as discussed below (cf. §4.5).

\subsection{Post-discharge ion current}

The ion current entering the post-discharge volume has been measured with a grid located at $5 \mathrm{~cm}$ downstream from the hole (cf. Table2). As a rough approximation, neglecting the field reinforcement on the edges of the central rings, these fits can be extrapolated above the hole leading to higher axial current density $(j(0))$ with the injected gas flow than without. Despite this rough approximation, the integrated currents from the extrapolated $J(r)$ over the hole surface are coherent with the ion current measured downstream the hole. It has to be noticed that this post-discharge current does not include ions collected on the walls of the hole as well as on the underlying earthed surface on the drilled plane electrode.

These ion losses are mainly due to ion selfrepulsion up to the walls. By analogy with electro-filtration, this EHD competition can be described by the ratio of the characteristic axial and radial times of ion in the hole $\left(t_{a x} / t_{r a d}\right)$ as described in [11]. $t_{a x}$ is the mean transit time of ion in the hole, it depends on the gas velocity, the axial electric field and the length of the hole. $t_{\text {rad }}$ is the mean time required to collect ion on the walls, it depends on the ion density in the hole and the diameter of the hole.

Table 2: Post-discharge ion current measured on the grid in the charging volume $I_{\text {grid }}$

\begin{tabular}{|c|c|c|c|}
\hline \multicolumn{1}{|c|}{$\mathrm{I}_{\text {grid }}(\mathrm{nA})$} & 0 & $5 \mathrm{Ipm}$ & $30 \mathrm{Ipm}$ \\
\hline $\mathrm{V}_{d}=-9 \mathrm{kV}$ & 1 & 18 & 150 \\
$\mathrm{I}_{d}=-30 \mu \mathrm{A}$ & & & \\
\hline $\mathrm{V}_{d}=-17 \mathrm{kV}$ & 1.5 & 80 & 380 \\
$\mathrm{I}_{d}=-110 \mu \mathrm{A}$ & & & \\
\hline
\end{tabular}

The increase of the gas flow from 5 to 30 L. $\mathrm{min}^{-1}$ leads to higher grid current, despite similar ion current density profile. Actually, the higher grid current at $30 \mathrm{~L} \cdot \mathrm{min}^{-1}$ is due to the reduction of ion losses in the hole, related to the reduced transit time in the hole. For a given flow rate, higher discharge current leads to higher grid current, but the increase of ion density in the hole leads to a higher fraction of ion collected on the walls of the hole. These results are out of the scope of the paper and are just presented to prove that $j(r)$ and postdischarge ion measurements are coherent.

\section{Discussion}

As described in detail in $\S 2$, the ion current density profile on the earthed plate $j(r)$ results from an EHD equilibrium. At each point in the gap, the ion current density depends on the product of the local ion density by the mean 
local velocity of ions related to both the electric field and the gas velocity (Cf. Eq. 1). The terms ion confinement is related to the modification of the ion current density profile measured on the plane, for a constant ion current on the plane (i.e. a constant discharge current which is the integral of the $j(r)$ over the surface of the plane), with higher ion current densities on the centre of the plane. Electrical and hydrodynamic ion confinements are analysed to explain the dominant mechanisms.

\subsection{Electrical confinement}

Without injected gas flow nor annular electrode (cf. \$4.1.2), the radius of the surface on the plane collecting all ions is defined by the trajectory of an ion at the limit of the space charge (here after referred as limit trajectory). This radius depends on the transit time of an ion on the limit trajectory from the point to the plane as well as the total outward radial electric field profile (Laplace and space charge electric fields) along ion trajectory. The transit time depends on the gap length and the axial electric field profile along ion trajectory.

With the polarized annular electrode (cf. §4.2), both the radial and axial components of the Laplace electric field are affected (cf. Figure 8)Erreur ! Source du renvoi introuvable..

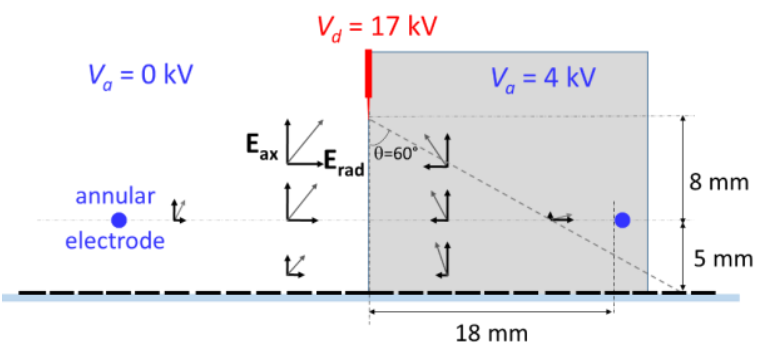

Figure 8. Schematic representation of radial and axial Laplace electric field in the gap with the annular electrode.

The total electric field including the space charge field has to be considered as detailed below. Actually, any modification of the Laplace electric field affects the trajectory of the ions and thus the distribution of the space charge. Then, for any constant discharge current, the evolution of the space charge electric field is discussed with respect to the modifications of Laplace electric field and related ion trajectory along each direction (radial then axial).

Considering firs the radial components only (i.e. neglecting axial modifications), the polarization of the annular electrode reduces the outward radial Laplace field (cf. Figure 8) and thus limits the radial outward drift of ions. It has to be underlined that the related increase of ion density partly compensates this effect.
Moreover, the axial component controls the ion drift time up to the plane and thus the duration of radial ion expansion.

Taking into account the axial components, the axial Laplace electric field is higher between the polarized annular electrode and the plane, and lower between the pointe and the annular electrode than without polarisation (cf. Figure 8). However, it is not possible to estimate the electric field taking into account the space charge electric field with these experiments without rough approximations. Whatever the axial electric field modification is, the polarized annular electrode induces higher current densities for $r<8 \mathrm{~mm}$ and lower further from the point axis than without (cf. \$4.2). In other terms, ion flux confinement towards the central symmetry axis is achieved in the low field region of discharge gaps by electrostatic focussing.

The ion current density on the centre of the plane $J(0)$ increases by $30 \%$ with the electrical ion flux confinement. However, hydrodynamic confinement leads to $20 \%$ increase of $J(0)$ without additional power supply that is more convenient for the final application, as depicted below.

\subsection{Hydrodynamic confinement}

By comparing $j(r)$ with and without gas injection in the gap (cf. \$4.4), ion hydrodynamic confinement has been highlighted. This ion hydrodynamic confinement close to the central axis is controlled by three processes detailed below.

The volume I is defined as the volume in which the gas velocity is lower than the electrostatics velocity of ions. In this volume, the ion trajectory is mainly governed by electrostatic forces and the gas velocity has a minor effect. In the volume II around the hole, the gas velocity is no more negligible compared to the ion velocity (dashed volume in Figure 9a and zone 3 in Figure 9b). 


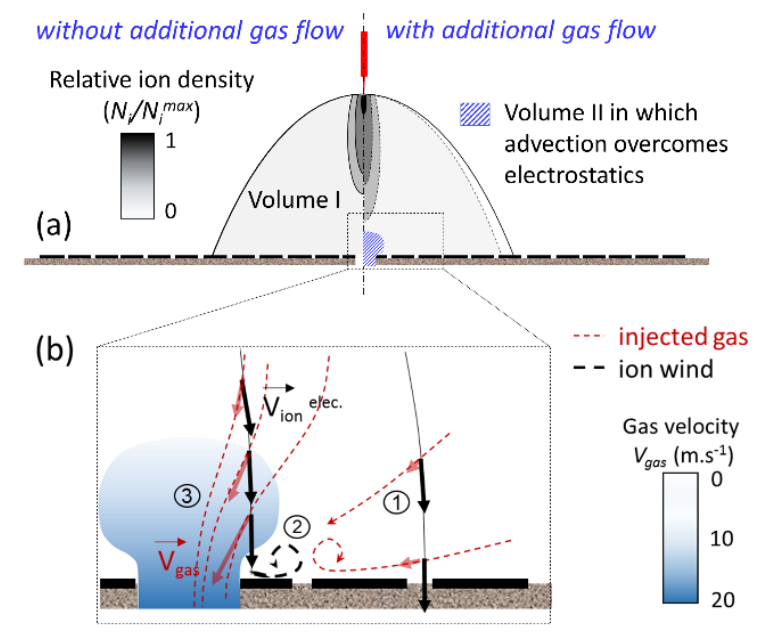

1) Radial component of $V_{\text {gas }}>V_{\text {ion }}$ elec.

$\rightarrow$ modification of ion trajectory due to advection

2) Vortexes around the hole

(crossflows of ion wind and injected gas flow)

3) lon draining $\rightarrow$ Hypothesis: $N_{i} У \rightarrow E_{\text {rad }} \downarrow \rightarrow$ ion confinement

Figure 9. Schematic description of (a) the effect of the axial component of flow velocity with electric field lines (full lines) and flow lines (dashed lines) (b) zoom around the hole with other processes proposed for the confinement of ions toward the central axis

The first process involved in ion confinement is based on the hydrodynamic transport of ions by advection due to the gas flow as already observed and modelled in different arrangements [15-16]. Both axial (schematized in Figure 9a even if negligible) and radial (cf. (1) in Figure 9b) components of the gas velocity are involved in ion trajectory modification.

The effect of the injected gas flow on ion velocity is negligible close to the point with injected gas velocity $\left(<1 \mathrm{~m} . \mathrm{s}^{-1}\right)$ much lower than ion velocities $\left(>100\right.$ m.s. $\left.{ }^{-1}\right)$. Despite negligible effect, the higher axial flow velocity related to gas injection in the gap reduces the ion transit time up to the plane and thus the same radial drift of ions occurs further from the point than without injected gas flow as schematized by the relative ion densities with and without injected gas flow in Figure 9a. The inward radial component of gas velocity increases with increasing gas flow rate which limits the radial expansion of the ions. If this effect can be neglected near the point, it has to be considered in the low electric field region of the gap close to the plane (cf. (1) in Figure 9b). The second process is related to the opposite direction of the electric wind sweeping over the plane from the centre to the walls, while the gas flow has an opposite direction (cf. (2) in Figure $9 b$ ). Then, gas turbulences are probably induced close to the hole and may affect ion trajectory, as already observed and modelled in [23]. Some ion can be trapped in gas vortexes that bring them back toward the centre of the plane.
The third process lies on the draining of ions into the hole. The mean gas velocity in the hole lies between 25 to $150 \mathrm{~m} . \mathrm{s}^{-1}$ for flow rates from 5 to $30 \mathrm{~L} \cdot \mathrm{min}^{-1}$. Hence, near the hole, the gas velocity reaches a few $\mathrm{m} . \mathrm{s}^{-1}$ close to the ion velocity. As a result, a potential reduction of the ion density just above the hole (where the gas velocity exceeds $10 \mathrm{~m} . \mathrm{s}^{-1}$ ) could induce a local reduction of the radial electric field close to the symmetry axis (cf. (3) in Figure 9b). This could account for a lower radial drift of ions above the plane and the related modification of the current density profiles.

Finally, the current density profile evolves with the gas flow up to a critical flow rate $Q_{c}$ and saturates for higher flow rates. This can be explained by the ion confinement in the low field region of the gap close to the central symmetry axis. Actually, the increase of the ion density around the hole is necessarily limited since higher space charge enhances radial electrostatic repulsions. Hence, once the critical space charge is reached, higher flow rates than the critical flow rate cannot affect anymore the ion current density profile due to the retro-control of the total radial repulsion field by increase of the space charge. As a result, coupling electrical and hydrodynamic confinement would still increase the confinement, but to a lower extend than the sum of both confinements.

\section{Conclusions}

To account for the effects of a polarized annular electrode and of a gas flow on the ion current distribution on the earthed plane of a corona discharge gap, an experimental setup has been developed. It is first validated for a full plane with respect to Warburg's law.

It has been shown that the $2 \mathrm{~mm}$ diameter hole drilled in the centre of the low field planar electrode does not affect the ion current density profile for $r>1.8 \mathrm{~mm}$ Hence, the gas flowing through the hole drilled in the planar electrode affects neither the electric field close to the point nor the subsequent electric wind.

As for the polarized annular electrode, the gas flow induces higher current densities for $r<8 \mathrm{~mm}$ and lower further from the point axis than without gas flow. The ion current density on the centre of the plane increases by $30 \%$ with the polarized annular electrode and by $20 \%$ with the gas flow rate. In other terms, ion flux confinement towards the central symmetry axis is achieved in the low field region of discharge gaps either by electrostatic focussing with a polarized annular electrode inserted in the gap or by hydrodynamic focussing with gas injected in the gap and blown from the discharge gap through the hole 
located at the centre of the plane. Since, this effect is retro-controlled by the space charge accumulation just close to the hole, this ion confinement does not evolve above $5 \mathrm{~L}$. $\mathrm{min}^{-1}$. Much higher gas flow rate would be required to compensate the so-increased radial space charge field.

EHD ion flux confinement to the central axis has been achieved. With the injected gas flow rate, the ion current density on the centre of the plane increases by $20 \%$ but the postdischarge ions current increases by two orders of magnitude due to the reduction of ion losses in the hole. This was the first step to ultimately evaluate the ion density in post-discharge aerosol chargers from the measured sizecharge relation, object of a future publication.

Acknowledgements: The authors wish to thank IRSN and CNRS for their financial support.

\section{References}

[1] H.R. Velkoff, I. Yamamoto, Electrohydrodynamics in an electrostatic precipitator, J. Fluid Mech. 108 (1981) 1-18.

[2] H. Nouri, N. Zouzou, E. Moreau, L. Dascalescu, Y. Zebboudj, Effect of relative humidity on current-voltage characteristics of an electrostatic precipitator, J. Electrostat. 70 (2012) 20-24.

[3] J.S. Chang, P.A. Lawless, T. Yamamoto, Corona discharge processes IEEE Trans, Plasma Sci. 19 (1991) 1152-1166.

[4] D. Carroll, I. Dzidic, R. Stillwell, K. Haegle, E. Horning, Anal. Chem, Atmospheric pressure ionization mass spectrometry. Corona discharge ion source for use in a liquid chromatograph-mass spectrometercomputer analytical system, Anal chem., 47 (1975) 2367-2373.

[5] C. Monge, R. Peyrous, B. Held, Optimization of corona wire-to-cylinder ozone generator: comparison with economical criteria, Ozone Sci. Eng. 19 (1997) 533-547.

[6] G. Artana, J. D'Adamo, L. eger, E. Moreau, G. Touchard, Study of the Flow Induced by a Sliding Discharge, Flow control with electrohydrodynamic actuators, AIAA J. 40 (9) (2002) 1773-1779.

[7] N. Konstantinos, X. Kiousis, Antonios. Moronis and D, Emmanouil. Fylladitakis, Ionic wind generation during positive corona discharge in a wire-cylinder air gap, International Journal of Engineering Science and Innovative Technology 4 (1) (2015)

[8] E. Warburg, Uber die spitzenentladung. Wied. Ann. 67 (1889) 6983.
[9] K. Adamiak, P. Atten, Simulation of corona discharge in point-plane configuration Journal of Electrostatics 61 (2004) 85-98.

[10] L. Zhao and K. Adamiak, EHD flow in air produced by electrical corona discharge in pin-plate configuration, J. of Electrostat., vol. 63, pp.337-350, 2005.

[11]K.T. Whitby, Generator for Producing High Concentrations of Small lons. Rev. Sci. Instrum., 32 (1961) 1351-1355.

[12] P. Intra, N. Tippayawong, Progress in unipolar corona discharger designs for airborne particle charging: A literature review. Journal of Electrostatics, 67 (2009) 605-615.

[13]M. Domat , F.E. Kruis , J.M. Fernandez-Diaz, Investigations of the effect of electrode gap on the performance of a corona charger having separated corona and charging zones.Journal of aerosol science, 68 (2014) $1-13$.

[14] J.P. Borra, N. Jidenko, E. Bourgeois, Atmospheric pressure plasmas for aerosols processes in materials and environment, The European Physical Journal Applied Physics, 47 (2009) 22804.

[15] Quast, N.R. Lalic, Measuring and Calculation of Positive Corona Currents Using the COMSOL Conference (2009) Milan. http://www.comsol.com/papers-presentations

[16] H. Ait Said, H. Nouri, Y. Zebboudj, Effect of air flow on corona discharge in wire-to-plate electrostatic Precipitator, Journal of Electrostatics 73 (2015) 19-25

[17] M. Robinson, Movement of air in the electric wind of the corona discharge AIEE Trans. 80 (1961) 143-50

[18] Y. Kondo and Y. Miyoshi, Pulseless Corona in Negative Point to Plane Gap, Jpn. J. Appl. Phys. 17 (1978) 643-649.

[19]A. Goldman, E.O. Selim, R.T. Waters, Current distribution in the negative corona discharge in air, Proceedings in the fifth GD, Liverpool (1978) 87-91.

[20]R. S. Sigmond, Simple approximate treatment of unipolar space-charge dominated coronas: the Warburg law and the saturation current. J. Appl. Phys. 53 (1982) 891-898.

[21]A. Goldman, M. Goldman, J.E. Jones, On the behaviour of the planar current distribution in the pulseless regime of negative DC point-plane coronas in air. In Proc. Tenth Int. Conf. on Gas Discharges and Applications 1992, Swansea, 270-273.

[22] Y. S.Akishev, M.E.Grushin, V. B.Karal'nik, I.V.Kochetov, A. E.Monich, A.P. Napartovich, N.I. Trushkin, Evolution of the Radial Structure of a Negative Corona during its Transformation into a Glow Discharge and a Spark Plasma Physics Reports, 29 (2) (2003) 176-186. 
[23]T. E. Allibone, J. C. Saunderson, Corona at very high direct voltages. V. Corona in rod/plane gaps. In Sixth Int. Symp. on High Voltage Engineering (ISH), New Orleans, (1989) Paper 22.02.

[24] J. E. Jones A theoretical explanation of the laws of Warburg and Sigmond. Proc. R. Soc. Lond. A 453 (1997) 1033-1052.

[25]K. Adamiak and P. Atten Numerical Simulation of the 2-D Gas Flow Modified by the Action of Charged Fine Particles in a Single-Wire ESP, 6th Conference of the "Société Française d'Electrostatique ", Paris \& Gif-sur-Yvette, 8-9 juillet 2008 (2008) 188-193.

[26] M. Aissou, H. Aitsaid, Hamou Nouri, and Youcef Zebboudj Analysis of current density and electric field beneath a bipolar DC wiresto-plane corona discharge in humid air Eur. Phys. J. Appl. Phys. (2013) 61. 